Notas y reseñas 



\section{Algunas consideraciones sobre el "laberinto endecasílabo", de sor Juana Inés de la Cruz}

En la Métrica española, de Antonio Quilis, se dice lo siguiente:

En español, todo verso simple tiene siempre un acento en la penúltima sílaba [...]. Un endecasílabo llevará siempre un acento en la décima sílaba, mientras que un decasílabo lo llevará en la novena [...].

Este acento, que es fijo en cada verso, y que, además, se repetirá en esa posición en todos los versos de la estrofa, se denomina acento estrófico, y es el más importante.

El acento estrófico es el que marca el ritmo de intensidad de cada verso:

Si la sílaba sobre la que va situado es de signo par, el ritmo es yámbico $[\ldots]$.

Si la sílaba sobre la que va situado es de signo impar, el ritmo es trocaico (34).

Ese "ritmo de intensidad" determinará la manera en la que los demás acentos del verso son clasificados: si éstos coinciden con el signo (par o impar) del verso (es decir, si son coincidentes con el signo del acento estrófico) son considerados acentos rítmicos. ${ }^{1} \mathrm{Si}$ todas las sílabas del mismo signo que el acento estrófico están acentuadas, el verso será rítmicamente pleno (por ejemplo, un endecasílabo acentuado en todas sus sílabas pares). Por otro lado, a los acentos que recaigan en una sílaba del signo contrario a la del acento estrófico se les conoce como extrarrítmicos, y aquellos acentos extrarrítmicos que, además, se encuentren en una sílaba contigua a otra que tenga acento rítmico son llamados antirritmicos. $^{2}$

${ }^{1}$ Ésta y las siguientes clasificaciones fueron tomadas de Quilis, Métrica española, 34-36.

2 "Téngase en cuenta que el término antirrítmico, como los demás, sólo se refiere a una determinada situación de las sílabas acentuadas, no indica una falta contra la 
He leído más de una vez a tratadistas metódicos que se empeñan en decir, por ejemplo, que acentuar un endecasílabo en quinta o en séptima constituye algo así como un pecado mortal (mucho más si la sexta sílaba es portadora de acento, como suele serlo). La tradición nos brinda múltiples ejemplos (en Garcilaso o en Góngora, en sor Juana o en Darío) para refutarlos contundentemente. Sin embargo, es cierto que los versos tienden a seguir la línea rítmica marcada por su acento estrófico, y tienden, también, a agruparse con otros versos que posean el mismo ritmo de intensidad. Ésa es la razón por la que la silva (o cualquier otra combinación de versos endecasílabos y heptasílabos) posee una riqueza rítmica tan evidente. Y bajo esa misma lógica se creó, siglos más tarde, lo que Tomás Segovia, en el prólogo a su traducción de Hamlet (Ediciones Sin Nombre / UAM, 2009), denomina silva modernista: una "silva" que contempla el uso de otros versos de signo yámbico, como el pentasílabo (unido tradicionalmente al heptasílabo en las seguidillas, por ejemplo), el eneasílabo, el tridecasílabo, y el doble heptasílabo, o alejandrino.

Tradicionalmente son pocas las construcciones estróficas que combinan versos con ritmos de intensidad distintos. Sin embargo, en "Avatares barrocos del romance", de Antonio Alatorre (utilizo las dos versiones: la de la NRFH, 26, 1977 y la de Cuatro ensayos de arte poética, 2007), encontramos un amplio repertorio de experimentaciones métricas que incluyen la unión de versos trocaicos con versos yámbicos dentro de una misma estrofa. Gracias a Góngora, el romance adquiere esa ductilidad que le permitirá ser el campo de mayor experimentación rítmica durante los Siglos de Oro, y aunque Góngora no escribió romances en los que se incluyeran versos con ritmos de intensidad distintos, su creación de romances heptasílabos (de signo yámbico, a diferencia del octosílabo, que era el verso del romancero viejo), su ruptura con la estructura estrófica tradicional del romance (la cuarteta), su producción de romances con estrofas heterométricas (de versos endecasílabos y heptasílabos combinados, por ejemplo) fueron la semilla que detonó esa apasionante experimentación, tan pulcramente documentada por Alatorre.

Un primer ejemplo de un romance que contempla la unión de versos yámbicos con trocaicos es el siguiente romance de Lope, de esquema 8-8-8-8-11-6-7:

No son, como dicen muchos, las rosas alejandrinas, al tiempo que se abren, nácar,

estética del verso: como todos los recursos de la versificación, este acento antirrítimico se justifica cuando se usa para conseguir un buen efecto estilístico" (Quilis, Métrica española, 36). 
coral cuando se marchitan, pero es verdad que se hallan en Jacinta soles en los ojos y perlas en la risa

(Alatorre, “Avatares barrocos...”, 2007, 34)

El efecto sonoro es, sin duda, muy especial: el endecasílabo, en este caso, significa una pausa que pone especial énfasis en la idea principal de la estrofa. Una vez expresada esta idea, la estrofa se apura a terminar; cae, pareciera, en cascada. Velozmente. Y pasa, además, algo muy curioso: los dos últimos versos son, el primero, trocaico, y el segundo, yámbico. Sin embargo, prácticamente no se nota diferencia rítmica entre ambos; es más, si no leyéramos cuidadosamente el poema (o más bien, si no leyéramos el poema tratando de analizarlo rítmicamente), podríamos pensar que los últimos dos versos son isométricos. ¿A qué se debe esto?

Tomás Segovia, en el prólogo ya citado anteriormente, introduce un concepto a la vez curioso y harto alumbrador en estos temas: el de métrica sumergida. Para explicarlo, Segovia nos dice que, para su oído, el eneasílabo es un endecasílabo sáfico (es decir, acentuado en octava) breve y el tridecasílabo, un endecasílabo alargado. Es decir, que en el endecasílabo están sumergidas u ocultas esas otras posibilidades de versificación, no tan comunes en español; que el verso más usado en nuestra tradición contempla o contiene, de alguna forma, esos otros versos que nos parecen raros. Apoyados en Quilis, comprendemos que la causa de ese fenómeno es la coincidencia del ritmo de intensidad entre esos versos, pero la forma en la que Segovia lo entiende nos hace plantearnos una pregunta esencial: ¿y por qué estos versos, si están contemplados en otro que usamos tanto, son usados tan poco?

Parecido al de Segovia es el siguiente ejemplo de Juan Caramuel, citado por Alatorre ("Avatares barrocos...", 1977, 354): lo que hace Caramuel, como se verá, es irle restando sílabas a un primer verso endecasílabo (es importante señalar que son las primeras sílabas las que resta), para obtener, a partir de esa operación, todos los versos simples posibles en el español (se verá que

${ }^{3}$ Digo "endecasílabo", a pesar de que Caramuel le llamaba "decámetro", resaltando así la importancia del acento en décima, aun por encima de la cantidad silábica. Con ese tipo de clasificación, Caramuel se ahorra las explicaciones necesarias cuando, ante la aparición de palabras agudas o esdrújulas en posición final, se requiere sumar o restar una sílaba al conteo "natural" del verso. En ese sentido, me parece más eficaz la clasificación de Caramuel; sin embargo, la tradición de los estudios métricos hace complicada su utilización: decir "decámetro" en lugar de "endecasílabo" podría parecer un exceso de cultismo y no una forma de buscar una designación métrica más eficaz. 
Caramuel no incluye el verso de dos sílabas; esto se debe a que él afirmaba su inexistencia):

Después que son la luz, que no reposa.

Pues que son la luz, que no reposa.

Que son la luz, que no reposa.

Son la luz, que no reposa.

La luz, que no reposa.

Luz que no reposa.

Que no reposa.

No reposa.

A pesar de provenir de procedimientos lógicos distintos, nada más gráfico que esta escalera escheriana de versos, que esta matruschka rítimica, para entender el concepto de "métrica sumergida" acuñado por Segovia. Sin embargo, el ejemplo de Caramuel plantea también otras preguntas, más parecidas a las que se plantearon algunos de los poetas barrocos: ¿si en el endecasílabo están contenidos todos los demás, qué pasa si mezclamos el endecasílabo también con versos pares?, ¿qué pasa si mezclamos versos pares con impares?

Volvamos al ejemplo de Lope. Nos habíamos preguntado por qué los dos últimos versos de la estrofa citada ("soles en los ojos / y perlas en la risa": un hexasílabo y un heptasílabo) sonaban tan parecido, a pesar de tener ritmos de intensidad distintos. Ahora bien, ¿qué pasa si le quito al segundo verso su primera sílaba? Me queda, brillando en el oído, un hexasílabo con exactamente el mismo patrón acentual que el hexasílabo anterior. La primera sílaba (no acentuada, por cierto) se vuelve, entonces, una especie de anacrusis. Este tipo de realidades sonoras nos demuestran que la poesía, como la lengua, no tiene categorías inmutables o absolutas.

Uno de los ejemplos más sorprendentes en los que se mezclan versos yámbicos con trocaicos es de sor Juana

[...] en cuya producción poética hay una variedad extraordinaria (no igualada, que yo sepa, por la de ningún otro autor) de romances compuestos en versos no octosílabos y en estrofas que no son la simple cuarteta [...]. Sor Juana es, en ese sentido, el poeta más representativo del Barroco español, su culminación más visible (Alatorre, supra, 341).

El ejemplo es el romance clasificado con el número 63, conocido como "Laberinto endecasílabo", el cual transcribo a continuación, para la fácil lectura 
de este texto (está puesto en boca de la condesa de Calve, quien felicita a su marido por su cumpleaños):

Amante,-caro, - dulce esposo mío, festivo y-pronto - tus felices años alegre - canta—sólo mi cariño, dichoso - porque - puede celebrarlos.

Ofrendas - finas - a tu obsequio sean amantes - señas - de fino holocausto, al pecho-rica-mi corazón, joya, al cuello-dulces - cadenas mis brazos.

Te enlacen - firmes, - pues mi amor no ignora, ufano - siempre, - que son a tu agrado voluntad-y ojos - las mejores joyas, aceptas - solas, - las de mis halagos.

No altivas - sirvan, - no, en demostraciones de ilustres - fiestas, - de altos aparatos, lucidas - danzas, - célebres festines, costosas - galas - de regios saraos.

Las cortas - muestras de - el cariño acepta, víctimas - puras de — el afecto casto de mi amor,- puesto - que te ofrezco, esposa dichosa,-la que,- - dueño, te consagro.

Y suple, - porque — si mi obsequio humilde para ti,—visto,- - pareciere acaso, pido que, — cuerdo, — no aprecies la ofrenda escasa y-corta, - sino mi cuidado.

Ansioso - quiere - con mi propia vida fino mi-amor-acrecentar tus años felices,- - y yo- quiero; pero es una, unida, - - sola, - - la que anima a entrambos.

Eterno-vive:-vive, y yo en ti viva eterna, - para que-identificados, parados - calmen - el Amor y el Tiempo suspensos - de que - nos miren milagros.

El juego, según la lectura tradicional, es el siguiente: el poema puede leerse de tres maneras: como romance endecasílabo (para lo cual habría que leer las tres columnas), como romance octosílabo (quitando la primera columna de la 
lectura), y como romance hexasílabo (leyendo sólo la última columna). ${ }^{4}$ Para ponerlo en sintonía con la gráfica de Caramuel podríamos plantear así las tres lecturas posibles del primer verso:

$\begin{array}{lr}\text { Amante, caro, dulce esposo mío, } & \text { (endecasílabo) } \\ \text { Caro, dulce esposo mío, } & \text { (octosílabo) } \\ \text { Dulce esposo mío. } & \text { (hexasílabo) }\end{array}$

Desde esta óptica no es tanto que sor Juana "mezcle" versos de distintas medidas (uno yámbico, dos trocaicos), sino que escribe un poema con tres lecturas posibles, independientes entre sí. Yo no estoy muy de acuerdo con esa lógica, pues me parece que limita las enormes posibilidades que este juego métrico permite. Sin embargo, volveré más adelante a este asunto.

Este tipo de ejercicios eran muy comunes en la época de sor Juana, sobre todo en la poesía de certamen. Méndez Plancarte en sus notas al poema de sor Juana menciona algunos autores con producciones semejantes (al que podríamos agregar el que comienza "Ardiendo - vivo - de Xavier el fuego [...]", citado por Alatorre, supra, 403), resaltando uno de D. Agustín de Salazar y Torres, cuya primera estrofa, según la cita de Méndez Plancarte, es la siguiente:

Aurora,-bello-nuncio de las luces,
dorado-Cenit, — centro de los rayos,
purpúrea—veloz,-Tarde voladora,
y negra—-Noche—-sombra del Ocaso [...].

A propósito, dice Alatorre: "El de Sor Juana está mejor trabado y, aunque sintácticamente complejo, es mucho más fluido y, sobre todo, responde mejor al reto de las tres lecturas" (supra, 451). Y sin duda era un reto difícil. La maestría de Sor Juana trasciende la imitación, como también la trasciende en el ro-

\footnotetext{
${ }^{4}$ Méndez Plancarte, en sus notas al poema (Sor Juana Inés de la Cruz, Obras completas, tomo I, Lírica personal, México, Fondo de Cultura Económica, 2001, 465-466), dice: "Esa estructura parecería fallar en el v.26; mas la primera sílaba sobrante del octosílabo o del exasílabo, se descuenta, por sinalefa con el verso anterior [...]. Tal compensación silábica era usual en las 'coplas de pie quebrado', donde a veces parecía alternar un pentasílabo, que de hecho no es sino tetrasílabo, pues su sílaba inicial se adjudicaba al octosílabo anterior, terminado en vocal o en agudo". Y cita algunos ejemplos de las famosas coplas de Manrique. Este tipo de licencias provoca que la música del poema se vuelva más variada y rica, al menos desde mi punto de vista.
} 
mance decasílabo que comienza "Lámina sirva el cielo al retrato [...]", escrito, de igual forma, imitando otro romance de Salazar y Torres. ${ }^{5}$

Así pues, queda claro que la forma de laberinto no fue invento de sor Juana, sino que estaba inserta en la tradición ultrabarroca. Al respecto de los laberintos, Alatorre, en sus notas al de sor Juana dice lo siguiente: "[...] hay varias formas de laberinto, pero en todas tiene gran importancia la tipografía; no son recitables, ni mucho menos cantables: se hace para deleite de los ojos" (Obras completas, tomo I, Lírica personal, 248-249). Creo que esta definición de Alatorre se aplica, impecablemente, a los Laberintos de Caramuel, por ejemplo, derroches matemáticos, pictóricos y lingüísticos que, efectivamente, están hechos para ser (ad) mirados. Sin embargo, no creo que ese mismo criterio sea aplicable para el poema de sor Juana. Aun siguiendo la lógica de las tres lecturas "sumergidas" en el texto, lo que es imposible es recitar o leer en voz alta, simultáneamente, esas tres lecturas. Pero leer o recitar cada una, de manera independiente, es, no sólo posible, sino sumamente agradable, rítmica y musicalmente.

$\mathrm{Al}$ respecto, sucede algo curioso con el laberinto de Salazar y Torres. A diferencia del de sor Juana (impreso con los guiones que separan las tres columnas), el de aquél forma parte de su "Loa a los tres años del rey" (es decir, de un texto dramático) y, en realidad, está escrito de la siguiente manera.

\begin{tabular}{|c|c|}
\hline Í́A & ¡Aurora, bello nuncio de las luces! \\
\hline EDA & ¡Bello nuncio de las luces! \\
\hline LEGRÍA & ¡Nuncio de las luces! \\
\hline Of & ¡Dorado Ceni \\
\hline & ¡Cenit, centro d \\
\hline ERRí & ¡Centro de los rayos! [...]. \\
\hline
\end{tabular}

Y más adelante de esta otra:

DíA

¡Aurora, bello nuncio de las luces!
¡Dorado Cenit, centro de los rayos!
purpúrea veloz, Tarde voladora,
y negra Noche, sombra del Ocaso [...].

${ }^{5}$ En este caso, trascendió tanto sor Juana en su imitación que, por años, varios autores le atribuyeron a ella el invento de esa forma de romance, como lo documenta Alatorre en "Avatares barrocos del romance", 158-161. 
EDAD

Alegría

¡Bello nuncio de las luces!

¡Cenit, centro de los rayos!

¡Veloz, Tarde voladora!

¡Noche, sombra del ocaso!

\author{
¡Nuncio de las luces! \\ ¡Centro de los rayos! \\ ¡Tarde voladora! \\ ¡Sombra del ocaso! (Elegir al enemigo, 7 )
}

Lo más curioso es que antes de estos diálogos, la didascalia indica "Canta el Día", en la primera cita, y "Cantan", en la segunda, para que después "prosigan representando", los mismos personajes, con diálogos octosílabos tradicionales. Además, después de la primera cita, la Alegría prosigue diciendo: “¿No advertís cómo en los ecos / la misma invocación suena / de Día, Edad y Alborozo, / dividiendo las cadencias?". Así pues, el modelo de sor Juana es un canto dramático, concebido como un laberinto de ecos, y no únicamente como un poema con tres posibles lecturas, escrito sólo para el deleite de los ojos.

Esto me da la pauta para hablar de por qué no estoy de acuerdo con clasificar este poema, únicamente, como un texto con tres (y ni una más) lecturas posibles. El juego laberíntico que propone el texto permite, desde mi punto de vista, ir mezclando las columnas al placer del lector, aunque con ciertas restricciones. Podemos empezar leyendo el primer verso como endecasílabo, los próximos tres como octosílabos, el primero de la segunda estrofa como hexasílabo, los dos siguientes como endecasílabos y, para cerrar este par de estrofas, un octosílabo. Así:
Amante, caro, dulce esposo mío, pronto tus felices años canta sólo mi cariño, porque puede celebrarlos.
A tu obsequio sean amantes señas de fino holocausto, al pecho rica mi corazón, joya, dulces cadenas mis brazos.

¡Y el poema sigue teniendo sentido! Pero no sólo tiene sentido, ¡sino que suena bien! (No es casualidad, por ejemplo, que los versos $6,8,10,16,23$ y 
32 del "Laberinto [...]" — en su lectura endecasilábica — tengan una estructura más dactílica que yámbica, lo que implica que estos versos tengan acento en séptima. ${ }^{6}$ Esto favorece, en una lectura que mezcle ambos metros, la unión con el octosílabo, además de darle gran riqueza a la composición endecasilábica por sí misma, a manera de un contrapunto barroco).

Las restricciones tienen un eje primordial: el del sentido. Con esto quiero decir que, ya que el ritmo no representa un problema combinatorio, el hecho de que el poema se siga entendiendo en las posibles lecturas que creemos debería ser nuestra principal limitante. En este sentido, leer sólo la primera o la segunda columnas no es posible, e incluir algunas partes de éstas en una lectura más libre como la que propongo tal vez sea posible, pero también puede resultar algo forzado, incluso rítmicamente.

Otra limitante que puede guiar nuestra libre creación de lecturas es la de la forma: la estructura del romance indica que en todos los versos pares debe conservarse la rima asonante. Bajo esta lógica, para hacer repeticiones ecoicas, como las del laberinto de Salazar y Torres, lo mejor sería que estas repeticiones comprendieran tiradas pares de versos continuos ( $\mathrm{y}$, de hecho, de preferencia, estrofas completas). Sin embargo, esta restricción es, para nuestras posibilidades como lectores, menos tajante que la del sentido: aunque no se conservara la forma, podríamos crear lecturas disfrutables conceptual y rítmicamente.

Dice Gorostiza, en sus "Notas sobre poesía":

que nada existe semejante a una libertad irrestricta. Todo está sujeto a medida, y la libertad puede no consistir en otra cosa que en el sentimiento de la propia posesión dentro de un orden establecido. Las reglas del ajedrez no oprimen al jugador, le trazan una zona de libertad en donde su ingenio se puede desenvolver hasta el infinito (Poesía, 15).

Sor Juana nos dejó un magnífico tablero en donde ejercitarnos. El número de nuestras posibilidades lúdicas dependerá de nuestro ingenio, de nuestra capacidad de seguir las reglas o de romperlas con inteligencia.

Emiliano ÁlvVarez

${ }^{6}$ El patrón acentual de un endecasílabo dactílico es el siguiente: óoo óoo óoo óo (acentos en 1, 4, 7 y 10). Esta estructura es también conocida como "gaita gallega". Así, el único plenamente dactílico es el verso 23. Los versos 6, 8, 10 y 16 se alejan sólo en un punto de esta estructura: su primer acento no está en la primera, sino en la segunda sílaba (así pues, podríamos decir que comienzan yámbica y se resuelven dactílicamente; es decir, que hay una inversión del pie métrico, después de la cuarta sílaba). Por último, en el 32, el patrón acentual es 2, 7, 10, en realidad más yámbico que dactílico, aunque conserva ese atípico acento que lo alía con el octosílabo. 


\section{REFERENCIAS}

Alatorre, Antonio, "Avatares barrocos del romance", en Cuatro ensayos de arte poética, México, El Colegio de México, 2007, 11-191.

Alatorre, Antonio, "Avateres barrocos del romance", Nueva Revista de Filología Hispánica, 26, 1977, 341-459.

CRuz, sor Juana Inés de la, Obras completas, t. I, Lírica personal, edición, introducción y notas de Antonio Alatorre, México, Fondo de Cultura Económica, 2009.

CRuz, Sor Juana Inés de la, Obras completas, t. I, Lírica personal, edición, prólogo y notas de Alfonso Méndez Plancarte, México, Fondo de Cultura Económica, 2001.

Gorostiza, José, Poesía, México, Fondo de Cultura Económica, 1964.

Quilis, Antonio, Métrica española, Madrid, Ariel, 6 ed., 1983.

Salazar y Torres, Agustín de, Elegir al enemigo, New York, Global Publications / Binghamton University, 2002.

SEgovia, Tomás, "Prólogo", en Hamlet, William Shakespeare, México, Ediciones Sin Nombre / Universidad Autónoma Metropolitana, 2009. 